See Article page 591.

\section{Commentary: Surgery for low-risk aortic valve replacement: The road to extinction}

\author{
Marco Moscarelli, MD, ${ }^{\mathrm{a}}$ and \\ Mario Gaudino, MD, PhD, MSCE ${ }^{\mathrm{b}}$
}

Aortic valve stenosis remains the most common valvular disease in elderly patients ${ }^{1}$ in developed countries. For several decades, surgical aortic valve replacement (SAVR) has been the only treatment for the more severe forms. However, during the past decade, new trials have changed the treatment landscape and recent evidence ${ }^{2,3}$ suggests that even low-risk patients with aortic valve stenosis can be treated by transcatheter aortic valve replacement (TAVR) after heart team discussion.

Johnston and colleagues ${ }^{4}$ show how, in high-volume centers, SAVR for low-risk patients provides excellent early outcomes and durable survival benefit, providing a solid benchmark for comparison with TAVR. Despite these outstanding results, it is unlikely that this work will slow down TAVR's penetration in the realm of low-risk patients for several reasons.

- SAVR is more invasive. Minimally invasive procedures still require a small surgical incision and the biological invasiveness remains the same (eg, general anesthesia, cardiopulmonary bypass, and aortic crossclamp). There is only limited evidence of the benefits of miniaturized circuit during valve surgery. Cardiologists (or surgeons who perform TAVR) accomplish the same anatomic result seen in open surgery using catheters; in simple words, the transcatheter procedure is the real minimally invasive approach.

- Adoption of minimally invasive AVR varies across countries and centers. The less-invasive techniques are difficult to master and not all surgeons are comfort-

From the ${ }^{\text {a Department }}$ of Cardiovascular Surgery, GVM Care \& Research Italy, Cotignola, Italy; and ${ }^{\mathrm{b} D e p a r t m e n t}$ of Cardio-Thoracic Surgery, Weill Cornell Medicine, New York, NY.

Disclosures: The authors reported no conflicts of interest.

The Journal policy requires editors and reviewers to disclose conflicts of interest and to decline handling or reviewing manuscripts for which they may have a conflict of interest. The editors and reviewers of this article have no conflicts of interest.

Received for publication March 3, 2021; revisions received March 3, 2021; accepted for publication March 4, 2021; available ahead of print March 9, 2021.

Address for reprints: Mario Gaudino, MD, PhD, MSCE, Department of Cardiothoracic Surgery, Weill Cornell Medicine, 525 E 68th St, New York, NY 10065 (E-mail: mfg9004@med.cornell.edu).

J Thorac Cardiovasc Surg 2023;165:606

$0022-5223 / \$ 36.00$

Copyright (c) 2021 by The American Association for Thoracic Surgery

https://doi.org/10.1016/j.jtcvs.2021.03.013

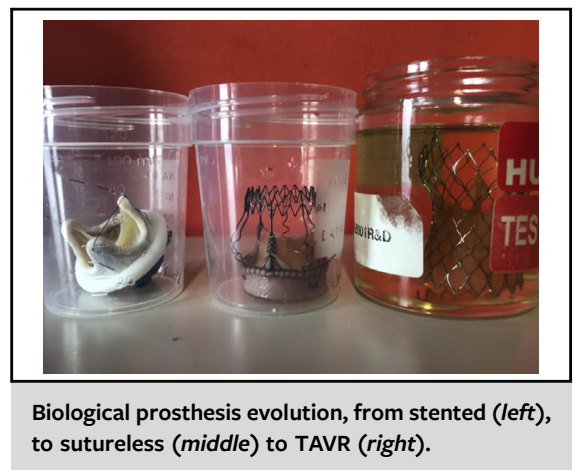

CENTRAL MESSAGE

Despite the excellent results of

surgical aortic valve replacement

for low risk patients, transcath-

eter aortic valve replacement will

likely become the treatment of

choice.

able with them. On the other hand, TAVR is an easy and very standardized procedure.

- Low-risk patients are generally those who get the most benefit from TAVR. Patients who undergo TAVR generally have very favorable vascular access and limited valvular calcifications and their chances of an easy and quick recovery are extremely high. These are also the patients who care the most about a fast recovery because they are generally active and productive.

- There are many human covariates that may influence the effect of surgery. Surgeons, anesthetists, perfusionists, nurses, and so on play a role in surgical interventions, whereas TAVR relies on the skill of very few operators.

It is time for surgeons to embrace the road that leads to the transcatheter skills; otherwise the surgical community will be left behind. Inability to evolve generally results in extinction.

\section{References}

1. Carità P, Coppola G, Novo G, Caccamo G, Guglielmo M, Balasus F, et al. Aortic stenosis: insights on pathogenesis and clinical implications. J Geriatr Cardiol. 2016;13:489-98.

2. Mack MJ, Leon MB, Thourani VH, Makkar R, Kodali SK, Russo M, et al. Transcatheter aortic-valve replacement with a balloon-expandable valve in low-risk patients. N Engl J Med. 2019;380:1695-705.

3. Popma JJ, Deeb GM, Yakubov SJ, Mumtaz M, Gada H, O'Hair D, et al. Transcatheter aortic-valve replacement with a self-expanding valve in low-risk patients. $N$ Engl J Med. 2019;380:1706-15.

4. Johnstone DR, Mahboudi R, Soltesz EG, Artis AS, Roselli EE, Blackstone EH, et al. Redefining "low risk": outcomes of surgical aortic valve replacement in low-risk patients in the transcatheter aortic valve replacement era. J Thorac Cardiovasc Surg. 2023;165:591-604.e3. 